\title{
Mechanical and thermal behaviour of biodegradable composites based on polycaprolactone with pine cone particle
}

\author{
KANISHKA JHA ${ }^{1,2, *}$, Y K TYAGI ${ }^{1}$ and AKESHWAR SINGH YADAV ${ }^{3}$ \\ ${ }^{1}$ Department of Mechanical Engineering, Dehradun Institute of Technology University, Dehradun 248001, India \\ ${ }^{2}$ School of Mechanical Engineering, Lovely Professional University, Phagwara 144411, India \\ ${ }^{3}$ Department of Metallurgical and Materials Engineering, Indian Institute of Technology, Roorkee 247667, India \\ e-mail: kanishkaero@yahoo.com; yogesh_tyagi30@yahoo.co.in; akeshwaryadav@gmail.com
}

MS received 14 March 2016; revised 27 December 2017; accepted 19 February 2018; published online 11 July 2018

\begin{abstract}
Polycaprolactone (PCL) was reinforced with natural fibres as they not only permit a substantial reduction of the material costs, but also play a role as reinforcement in mechanical properties. This work was focused on the estimation of mechanical and thermal behaviour based on PCL and Pine Cone particles (PCP) filler at different weight percentages $(0,5,10,15,30$ and $45 \mathrm{wt} \%)$. Tests results indicated considerable improvement in mechanical properties, corresponding to a gain in impact strength and \% elongation of 6 and $9.2 \%$ at $15 \mathrm{wt} \%$ particle loading, respectively. Some decrease in thermal stability was observed for composites with increasing filler content where as composite at $15 \%$ PCP was not significantly affected. Lower melting and crystallization enthalpies and higher crystallinity values were obtained for bio-composites compared with neat PCL. Some decrease in thermal stability and increase in oxygen and water vapour barrier properties were also observed for composites with increasing filler content.
\end{abstract}

Keywords. Impact strength; pine cone; polycaprolactone; scanning; electron; microscope.

\section{Introduction}

The thriving applications of plastics in every segment of life have increased plastic waste alarmingly [1]. Therefore, in the last decade, there was growing interest in the use of green composites because of their comparable mechanical properties, chemical resistance, water resistance, better processabillity and low cost $[2,3]$. As the e-waste generation is a global issue, structural body panels for electronic items needs good impact resistance and have to be eco-friendly [2]. Many non-biodegradable petroleum-based polymers such as polypropylene, polyethylene and polystyrene have raised several environmental issues including waste generation, accumulation in disposal system and reproducibility, thereby increasing the volume of commercial and industrial dumps [3]. On the other hand, there is a wide range of natural or synthetic polymers degrade by hydrolytic (polyglycolide, polylactides, polydioxanone, polycaprolactone, polyhydroxyalkanoates) and enzymatic (polysaccharides, protein, polyaminoacids) route $[2,4]$. Polycaprolactone belongs to aliphatic polyesters and is easily available as a biodegradable polymer having good mechanical strength, flexibility and also hydrophobic in nature. The PCL undergoes slow hydrolytic degradation because of the presence of aliphatic ester linkages. Because of its excellent biocompatibility,

*For correspondence
PCL application has also intensively investigated for tissue engineering [5]. Vilaplana et al [6] in his review article mentioned that in PCL bio-composites, presence of natural fiber may promote the early degradation of the composite. In many other articles researchers quoted that PCL is easily degraded by enzymatic actions [7-10]. Conventional plastics like polypropylene and polyethylene, requires hundreds or even thousands of years to degrade completely. On the other hand, PCL degrades in a few years [3, 11]. The Green nature of the polymer composite materials can be increased substantially by using fibers and grains of biodegradable materials that will retain mechanical strength to replace the existing synthetic fibers [12]. Several studies in the past have made to develop new composites from biodegradable polymers $[10,13]$. In a study, composites of PLA and Hemp fibre were prepared, with significant improvement in tensile properties [14]. Different fiber treatments were incorporated to enhance the mechanical properties, in a similar study areca nut fibre reinforced PCL based unidirectional composites were fabricated by compression moulding in study. Composites made of areca nut fibre treated with $4 \%$ silane and at $500 \mathrm{Krad}$ dose of gamma irradiation showed the highest mechanical properties [15]. Another group of researchers studied the different loading of rice straw fibre in PCL matrix. They observed that $5.0 \mathrm{wt} \%$ rice straw is sufficient to enhance the tensile strength, and the highest tensile strength which was observed at $5.0 \mathrm{wt} \%$ and rice straw 
loading is $23.44 \mathrm{MPa}$ [16]. In the present study, green composites of Polycaprolactone (PCL) and Pine Cone Powder (PCP) were fabricated and the effect of reinforcement of PCP at different wt\% in PCL matrix were investigated for their mechanical, morphological and water resistance properties. The use of natural fibers as a potential reinforcement in polymer matrix composites are well-cited in numerous literatures. However, the natural fiber-reinforced polymer matrix composites are concerned by the highly polar and hydrophilic nature of lignocellulosic fibers, which result in a poor interfacial adhesion compatibility with hydrophobic polymer matrix, which led to degraded mechanical and thermal properties [17].

In the present work, polymer composites were developed with melt blending technique. Polycaprolactone was used as the matrix polymer and with pine cone particle (PCP) as the reinforcement ( $0-45 \%$ weight fraction), and thereby reducing the overall cost of the product. This study was undertaken to evaluate the mechanical and thermal characteristics of bio-composites. Pine cone was added in polycaprolactone by varying weight fraction and stable thermal properties was observed whereas impact and elongation properties first increase and then decrease on increasing pine cone weight fraction. The results were analysed with several polymer-particle combinations describing the level of interaction between the two phases.

\section{Experimental}

Polycaprolactone (CAPA 6800) with molar mass $80,000 \mathrm{~g} / \mathrm{mol}$ was obtained from Sigma Aldrich. Pine Cones (PC) were collected from the stone pine (Pinus pinea L.) in the Dehradun District of Uttarakhand, India. Pine tree cones in grounded form was used as reinforcement. The pine cones without nuts soaked in a hot water for $4 \mathrm{~h}$ at $90^{\circ} \mathrm{C}$. Soaking of pine cones was believed to partially remove the gum from the surface of the cones and impart the grind ability and bonding properties to the cone particles. After the soaking, the wet cones were dried in an oven at $60^{\circ} \mathrm{C}$ for $10 \mathrm{~h}$ to moisture content of $20-30 \%$ based on the oven-dry cone weight as per ASTM D4442. Following the drying, the cones then processed by a rotary grinder without adding additional water. Finally, the cone particles passing through a 35-mesh screen and was retained by an 80-mesh screen (figure 1). The cone particles will then have been dried in a laboratory oven at $85^{\circ} \mathrm{C}$ for $4 \mathrm{~h}$ [18].

Specimen sheets were prepared by compression molding using Delta Malikson Pressman $100 \mathrm{~T}$ (India) at $150^{\circ} \mathrm{C}$, to produce sheets of $3.2 \pm 0.4 \mathrm{~mm}$ thickness for various tests. Materials were successively pressed under $1 \mathrm{MPa}$ (2 min), $3 \mathrm{MPa}(2 \mathrm{~min})$ and $5 \mathrm{MPa}(5 \mathrm{~min})$ to eliminate the trapped air pockets. Before performing mechanical tests, the composite specimens were prepared as per ASTM standard and conditioned on ambient values of $23 \pm 2{ }^{\circ} \mathrm{C}$ and $50 \pm 5 \%$ relative humidity for $48 \mathrm{~h}$. The impact test (Izod) was performed according to ASTM D256 standard using an impact tester (IZOD Impact Tester). The tensile tests of the specimens were carried out as per the ASTM D638 standards using a Universal Testing Machine of model LR $100 \mathrm{~K}$, Lloyd U.K., at a crosshead speed of $2 \mathrm{~mm} / \mathrm{min}$. The flexural strength of the samples was measured by Universal testing machine of model LR 100K, Lloyd, U.K., according to ASTM D790. The crosshead speed was $2 \mathrm{~mm} / \mathrm{min}$ and the support span length were $48 \mathrm{~mm}$. Micrographs SEM images of the prepared composites were recorded by using SEM (LEO 435VP).

\section{Results and discussion}

In polymers, incorporation of a rigid filler significantly decreases the ductility of the polymer matrix, which is measured as the strain percentage in a stress- strain curve.

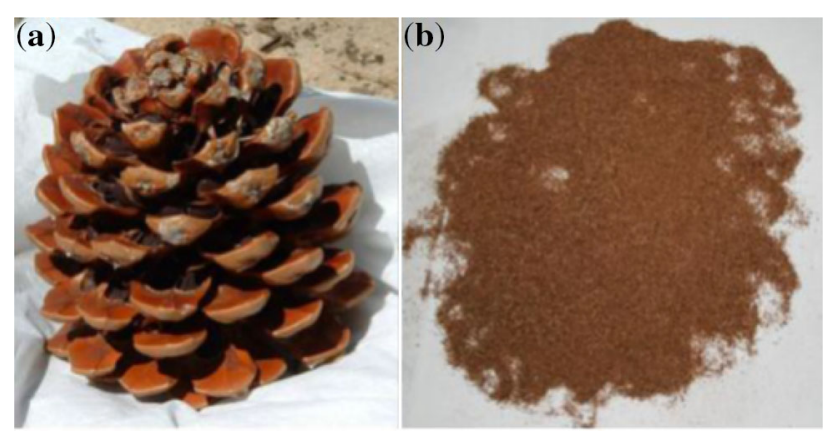

Figure 1. (a) Pine cone and (b) pine cone particle.

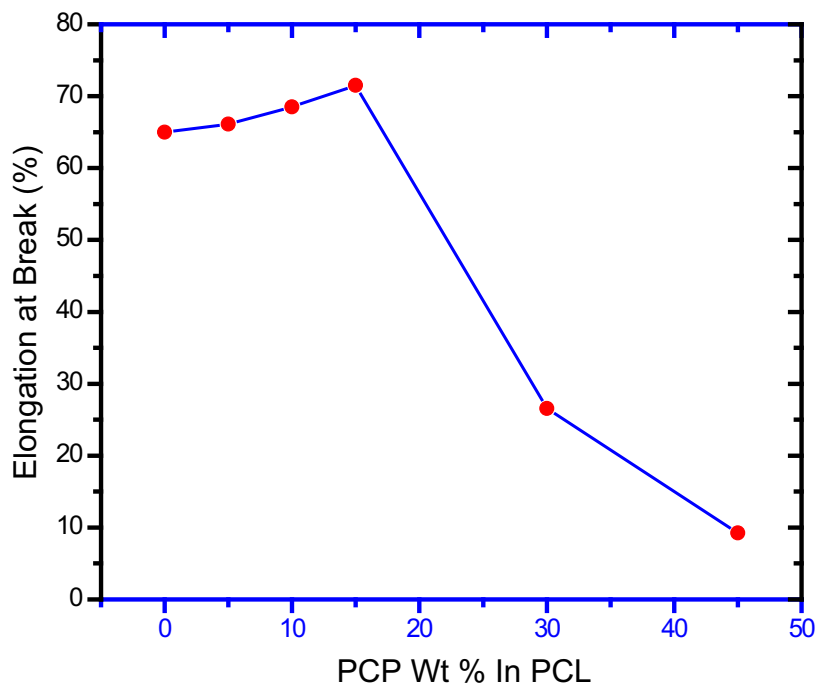

Figure 2. Impact strength of PCL-PCP composites. 


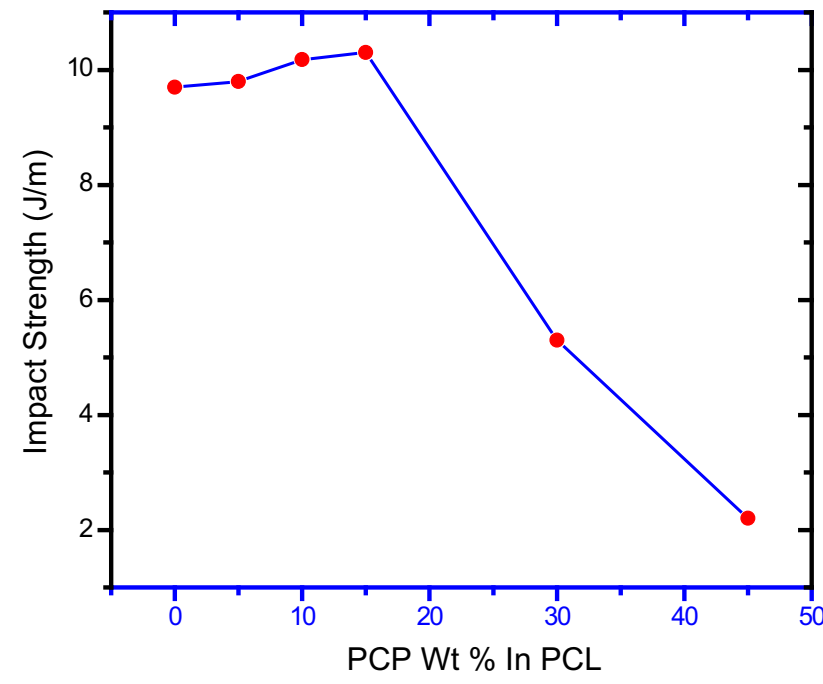

Figure 3. Percentage elongation of PCL-PCP composite.

The samples of PCL-PCP composites were tested for impact strength, \% elongation, tensile and flexural strength. The graphs of the results have been shown in figures 2-4. The graphs in figures 2 and 3 have shown very slight increase in impact strength and in $\%$ elongation at $5 \%$ and $10 \%$, and considerable improvement by $6 \%$ and $9.2 \%$ at $15 \mathrm{wt} \%$ of PCP loading in comparison to neat PCL. Up to $15 \%$ PCP, the elongation of the PCL-PCP composites was greater than $109 \%$ and at 30\% PCP and higher, the elongation decreased dramatically. For all weight fraction of PCP, the elongation results of pure PCL were in agreement with previous outcomes. In contrast, the elongation values for other PCL composites showed linear behaviour because the reinforcement was limited to two data points [19].

The tensile and flexural strength linearly decreased as PCP content increased. PCL filled with other agricultural materials (starch, zein, and wood flour/lignin) showed similar reductions in tensile strength as the filler amount increased [19-22]. Decrement in mechanical strengths and $\%$ elongation for higher weight fraction of PCP was attributed to the existence of large agglomerates which makes the composite more brittle or stiff because the fibre/particulate restricted the polymer chain elongation [18] and the uneven dispersion of PCP in the PCL matrix, as shown in figure 5 . The weak interfacial bonding between PCP/PCL results in poor tensile and flexural properties as shown in figure $3 a$ and $b$, which hampers the stress transfer $[23,24]$ from the matrix to filler resulting in reduction of flexural strength with an increase in wt\% of PCP [25].

The thermal stability of pine cone particles and PCL matrix containing particles $(5,10,15,30$ and $45 \mathrm{wt} \%)$ was studied by DTG, DTA and TGA under air from the ambient temperature to $1000^{\circ} \mathrm{C}$. The onset of thermal degradation can be identified by a sudden decrease in sample weight. The difference is due to the endothermic and exothermic combustion reactions taking place. Thermal degradation at $15 \mathrm{wt} \%$ shows higher degradation temperature at different stages than 5 and $10 \mathrm{wt} \%$ and then decreased for further incorporation of fiber. The TGA plot of $15 \mathrm{wt} \%$ samples show four loss steps. The initial weight loss $(\sim 0.8 \%)$ observed between $27^{\circ} \mathrm{C}$ and $98^{\circ} \mathrm{C}$ is attributed to the evaporation of the water from the particles, while the beginning of degradation in samples observed at higher temperature i.e., after $250^{\circ} \mathrm{C}$. Above this temperature it can be observed that the thermal stability of the samples was continuously decreasing. In particular, the 1st stage $\left(250-355^{\circ} \mathrm{C}\right)$ was accounted for the thermal decomposition of hemicellulose and pectin [25] (26\% of weight loss), 2nd stage occurs in the range $\left(350-414^{\circ} \mathrm{C}\right)$ and associated to the degradation of cellulose content in the particle $(50 \%$ of weight loss) [26]. The $3 \mathrm{rd}$ stage $\left(414-440^{\circ} \mathrm{C}\right)$ was reasoned for the degradation of lignin ( $7.5 \%$ of weight loss). Similar

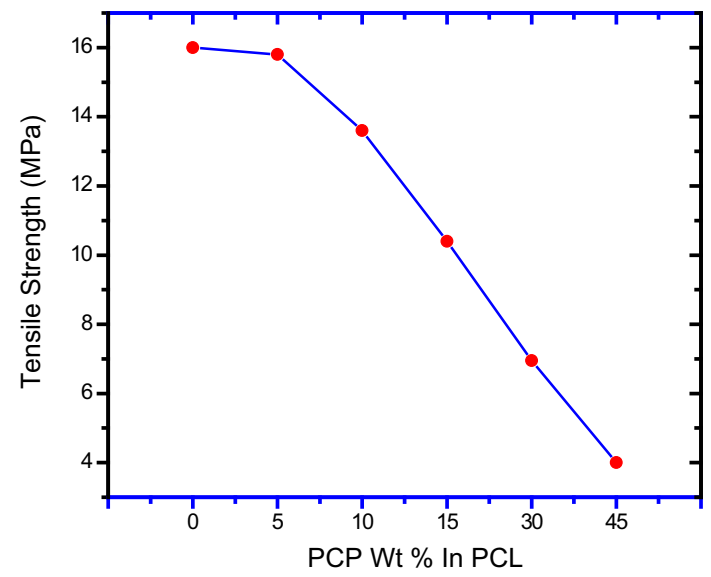

(a)

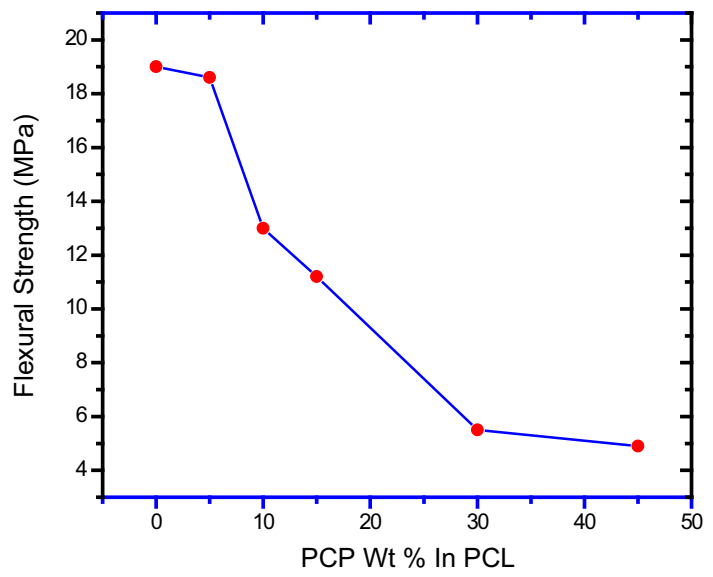

(b)

Figure 4. Mechanical strengths of PCL-PCP composites. 

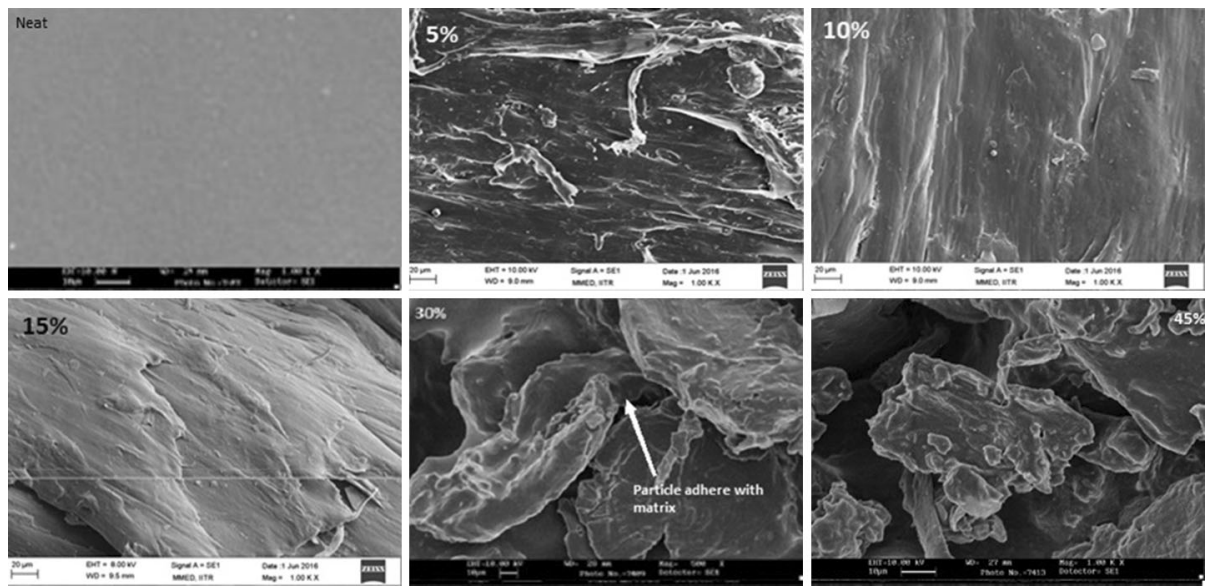

Figure 5. PCL-PCP composites with neat PCL and fiber at 5, 10, 15, 30 and $45 \mathrm{wt} \%$ of PCP.

Table 1. TG values for bio-composites.

\begin{tabular}{lcccc}
\hline Samples & 1 st Stage & 2nd Stage & 3rd Stage & 4th Stage \\
\hline $5 \mathrm{wt} \%$ & $243-348^{\circ} \mathrm{C}$ & $348-410^{\circ} \mathrm{C}$ & $410-436^{\circ} \mathrm{C}$ & $436-456^{\circ} \mathrm{C}$ \\
$10 \mathrm{wt} \%$ & $247-351^{\circ} \mathrm{C}$ & $351-412^{\circ} \mathrm{C}$ & $412-436^{\circ} \mathrm{C}$ & $436-459^{\circ} \mathrm{C}$ \\
$15 \mathrm{wt} \%$ & $250-355^{\circ} \mathrm{C}$ & $355-414^{\circ} \mathrm{C}$ & $414-440^{\circ} \mathrm{C}$ & $440-462^{\circ} \mathrm{C}$ \\
$30 \mathrm{wt} \%$ & $239-314^{\circ} \mathrm{C}$ & $314-406^{\circ} \mathrm{C}$ & $406-449^{\circ} \mathrm{C}$ & $449-467^{\circ} \mathrm{C}$ \\
$45 \mathrm{wt} \%$ & $233-333^{\circ} \mathrm{C}$ & $333-407^{\circ} \mathrm{C}$ & $407-427^{\circ} \mathrm{C}$ & $427-448^{\circ} \mathrm{C}$ \\
\hline
\end{tabular}

Table 2. DTA values for bio-composites.

\begin{tabular}{lcc}
\hline Samples & 1 st Peak & 2nd Peak \\
\hline $5 \mathrm{wt} \%$ & $404^{\circ} \mathrm{C}$ & $452^{\circ} \mathrm{C}$ \\
$10 \mathrm{wt} \%$ & $407^{\circ} \mathrm{C}$ & $459^{\circ} \mathrm{C}$ \\
$15 \mathrm{wt} \%$ & $410^{\circ} \mathrm{C}$ & $464^{\circ} \mathrm{C}$ \\
$30 \mathrm{wt} \%$ & $402^{\circ} \mathrm{C}$ & $467^{\circ} \mathrm{C}$ \\
$45 \mathrm{wt} \%$ & $403^{\circ} \mathrm{C}$ & $453^{\circ} \mathrm{C}$ \\
\hline
\end{tabular}

trends were observed for 30 and $45 \mathrm{wt} \%$ samples and their values are given in table 1.

The DTA plots of $15 \mathrm{wt} \%$ sample show different peaks representing degradations reactions of hemicelluloses, pectin, cellulose and lignin. The 1 st exothermic peak was at $410^{\circ} \mathrm{C}$ corresponding to the decomposition of cellulose which leads to the formation of volatile compounds (table 2). The 2 nd exothermic peak at $464^{\circ} \mathrm{C}$ is accounted for the oxidation of volatile compounds [27, 28]. Similar results were noticed for samples at 30 and $45 \mathrm{wt} \%$ and tabulated below. SEM micrographs for different weight percentages $(15,30$ and $45 \%)$ of PCP in PCL have been shown in figure $5 \mathrm{a}, \mathrm{b}, \mathrm{c}$ and $\mathrm{d}$. Composites with $15 \mathrm{wt} \%$ of PCP have comparatively better adhesion around the PCP particles as compared to 5, 10, 30 and $45 \mathrm{wt} \%$. Since it has been reported that the formation of hydrogen bonds between the PCP and the disparate hydrophilicities of PCL result in less efficient adhesion observed for higher weight fractions of PCP [29].

The uneven agglomeration of PCP in bundles can also be observed in SEM images and found to be maximum for composites with $45 \mathrm{wt} \%$ of PCP. Micrographs have shown potential voids for water accumulation which hamper adhesion and water resistance properties (table 2).

\section{Conclusion}

Green composites were developed based on Polycaprolactone (PCL) and Pine Cone Particles (PCP). PCP was incorporated into PCL (up to $45 \mathrm{wt} \%$ ) as a reinforcement to develop a biodegradable polymer composite. Microscopy of the composites showed uniformly dispersed PCP particle around PCL matrix at higher level of reinforcement. Significant improvement in impact strength and \% elongation was observed with the addition of Pine Cone Particles (PCP) at $15 \mathrm{wt} \%$ in PCL matrix indicating the potential use of this filler as reinforcement agent in PCL composites. Whereas tensile and flexural strength of the composites were decreased as fiber loading increases due to lack of compatibility between matrix and fiber and thus less stress transfer, resulting in failure of the specimen. The evaluation of the thermal properties of polycaprolactone-based pine cone particle composite depicts no significant change in thermal properties with the varying weight fraction of PCP. Decomposition temperature decreases from $250^{\circ} \mathrm{C}$ to $233^{\circ} \mathrm{C}$ with the increase in particle loading from 5 to $45 \mathrm{wt} \%$. SEM micrographs have revealed the presence of voids in the vicinity of pine cone particles at higher weight percentage of PCP loading. In conclusion, as the transparency issue is not present, it could be used for the fabricating green and sustainable materials like food trays, food containers and similar products. 


\section{Acknowledgements}

The Authors are grateful to the Director of Institute Instrumentation Centre, India Institute of Technlogy, Roorkee, Uttarakhand and CIPET, Govt. of India, Amritsar, Punjab for their support in the characterization of the green composites. Also, for DIT University for partial funding of the research.

\section{References}

[1] Bogoeva-Gaceva G 2013 Biocomposites based on poly (lactic acid) and kenaf fibers: effect of microfibrillated cellulose. Maced. J. Chem. Chem. Eng. 32(2): 331-335

[2] Hung S J and Edelman P G 1995 An overview of biodegradable polymers and biodegradation of polymers. In: Degradable Polymers: Principles and Application, eds. G Scott and D Gilead, 8-24. London: Chapman \& Hall

[3] Chiellini E, Cinelli P, Chiellini F and Imam S H 2004 Environmentally degradable bio-based polymeric blends and composites. Macromol. Biosci. 4:218-231

[4] Wu C S 2003 Physical properties and biodegradability of maleated polycaprolactone / starch composite. Polym. Degrad. Stab. 80: 127-34

[5] Naira L S and Laurencin C T 2007 Biodegradable polymers as biomaterials. Prog. Polym. Sci. 32:762-798

[6] Vilaplana F, Stromberg E and Karlsson S 2010 Environmental and resource aspects of sustainable bio-composites. Polym. Degrad. Stab. 95: 2147-2161

[7] Tokiwa Y, Calabia B, Ugwu C and Aib S 2009 Biodegradability of plastics. Int. J. Mol. Sci. 10: 3722-3742

[8] Bisanda E T N and Ansell M P 1999 The effect of silane treatment on the mechanical and physical properties of sisalepoxy composites. Compos. Sci. Technol. 141: 165-178

[9] Pavithran C, Mukherjee P S, Bramakumar M and Damodaran A D 1987 Impact properties of natural fiber composites. $J$. Mater. Sci. Lett. 7: 882-889

[10] Chin-San Wu and Hsin-Tzu Liao 2012 Polycaprolactonebased green renewable eco-composite made from rice straw fiber: characterization and assessment of mechanical and thermal properties. Ind. Eng. Chem Res. 51:3329-3337

[11] Bledzki A K and Gassan J 1999 Composites reinforced with cellulose based fibres. Prog. Polym. Sci. 24(2): 221-274

[12] Kabir M M, Wang H, Aravinthan T, Cardona F and Lau K T 2011 Effects of natural fiber surface on composite properties: a review. In: eddBE Proceedings, pp. 94-99

[13] Ashori A and Nourbakhsh A 2009 Mechanical behavior of agro-residue-reinforced polypropylene composites. J. Appl. Polym. Sci. 111(5): 2616-2620

[14] Shakoor A, Muhammad R, Thomas N L and Silber Schmidt V V 2013 Mechanical and thermal characterisation of poly (l-lactide) composites reinforced with hemp fibers. J. Phys. Conf. Ser. 451: 012010

[15] R Khandanlou, MB Ahmad, K Shameli, MZ Hussein, N Zainuddin and K Kalantari 2014 Mechanical and thermal stability properties of modified rice straw fiber blend with polycaprolactone composite. J. Nanomater. 675258: 9
[16] Kamol Dey, Sumon Ganguly, Ruhul A Khan and Mubarak A Khan 2013 Surface treatment of areca-nut fiber using silane and gamma irradiation: fabrication of polycaprolactone based composite. J. Compos. Biodegrad. Polym. 1: $1-7$

[17] Bakare I O, Okieimen F E, Pavithran C, Abdul Khalil H P S and Brahmakumar M 2010 Mechanical and thermal properties of sisal fiber-reinforced rubber seed oil-based polyurethane composites. Mater. Des. 31(9): 4274-4280

[18] Turker Dundar, Nadir Aryrilmis and Umit Buyuksari 2010 Utilization of waste pine cone in manufacture of wood/plastic composite. In: 2nd International Conference on Sustainable Contruction Material and Technologies 28th30th June. Universita politecnica Delle Marche, Ancona, Italy

[19] Corradini E, Mattoso L H C, Guedes C G F and Rosa D S 2004 Mechanical, thermal and morphological properties of poly(e-caprolactone)/zein blends. Polym. Adv. Technol. 15: 340-345

[20] Odusanya O S, Ishiaku U S and Azemi B M 2000 On Mechanical Properties of Sago Starch/Poly(\&-caprolactone). Compos. Polym. Sci. Eng. 40: 1298

[21] Ishiaku U S, Pang K W, Lee W S and Ishak Z A M 2002 Mechanical Properties and Enzymic Degradation of Thermoplastic and Granular Sago Starch Filled Poly(EpsilonCaprolactone). Eur. Polym. J. 38 (2): 393-401

[22] Nitz H, Semke H, Landers R and Mulhaupt R 2001 Reactive extrusion of polycaprolactone compounds containing wood flour and lignin. J. Appl. Polym. Sci. 81: 1972-1984

[23] Essabir H, Nekhlaoui S, Malta M, Bensalah M O, Arrakhiz F Z, Qaiss A and Bouhfid R 2013 Bio-composites based on polypropylene reinforced with almond shells particles: mechanical and thermal properties. Mater. Des. 53: 225-230

[24] Noel Ibrahim Akos, Mat Uzir Wahit, Rahmah Mohamed and Abdirahman Ali Ususf 2013 Comparative studies of mechanical properties of polycaprolactone and poly(lactic acid) blends reinforced with natural fibers. Compos. Interfaces 20(7): 459-467

[25] Wahit M U, Akos N I and Laftah W A 2013 Influence of natural fibers on the mechanical properties and biodegradation of poly(lactic acid) and poly(e-caprolactone) composites: a review. Polym. Compos. 33(7): 1045-1053

[26] Valdés A, Beltrán, A and Garrigós MC 2013 Characterization and classification of almond cultivars by using spectroscopic and thermal techniques. J. Food Sci. 78(2): C138C144

[27] Reixach R, Espinach F, Franco-Marqués E, Ramirez de Cartagena F, Pellicer N, Tresserras J and Mutjé P 2013 Modeling of the tensile moduli of mechanical, thermomechanical, and chemi-thermomechanical pulps from orange tree pruning. Polym. Compos. 34(11): 1840-1846

[28] Sergio N M, Veronica Calado, Ruben Jesus S Rodriguez and Frederico M Margem 2012 Thermogravimetric behavior of natural fibers reinforced polymer composites-an overview. Mater. Sci. Eng. A557: 17-28

[29] Dayma N and Satapathy B K 2010 Morphological interpretation and micromechanical properties of polyamide-6/ polypropylene-grafted-maleic anhydride/nanoclay ternary nanocomposites. Mater. Des. 31(10): 4693-4703 